\title{
DECISIONS
}

\section{A 38-year-old man who uses crack cocaine}

\author{
Amy H.W. Sur MD, Lawrence C. Loh MD MPH
}

After exposure to a roommate diagnosed with active tuberculosis (TB), a 38-year-old man presents to a rural primary care clinic. During this visit, he discloses chronic, inhalationexclusive use of crack cocaine. He denies concurrent or previous injection use of crack cocaine or other illicit drugs. He discloses his fears of exposure to not only TB, but other infections such as HIV and hepatitis C.

\section{What questions should the patient be asked about his substance use?}

Provided the patient is not acutely intoxicated, a thorough history of substance use should be taken, focusing on identifying concurrently used substances, quantities and frequency of consumption, routes of administration, and noted desired and undesired health effects. ${ }^{1}$ Detailed questioning should assess severity of use, dependence and/or withdrawal signs, prior treatment, impact on function, and financial, relational and legal implications of use.

Social history should identify other risk factors (e.g., homelessness, sex work, involvement in criminal activity, peer network of users) and protective factors (e.g., employment, supportive peers). Examination of medical, psychiatric and family history will further stratify risks related to concurrent disorders. Assessment of patient insight, motivation and preferences regarding treatment will help increase the likelihood of adherence with tailored interventions. The use of a validated instrument, such as the Addiction Severity Index (www.tresearch.org/tools/ download-asi-instruments-manuals), may aid in systematically reviewing these key domains. ${ }^{2}$

\section{What should be included in the physical examination?}

Multiple organ systems can be affected directly by crack cocaine use. These include short- and long-term changes to the cardiovascular, respiratory, neurologic, gastrointestinal and renal systems. Patients may also experience skin lesions, reproductive problems and psychiatric conditions, such as dysphoria, anxiety and psy- chosis (Appendix 1, available at www.cmaj.ca/ lookup/suppl/doi:10.1503/cmaj.150491/-/DC1). ${ }^{1}$

The most prominent risks to examine for arise from potential cardiovascular morbidity. Acutely, the sympathomimetic stimulant properties of cocaine can cause instability in vital signs and altered mental state. Cardiovascular examination may similarly reveal arrhythmia or extra heart sounds, suggesting cardiac injury associated with chronic use. Patients who inhale should have a detailed respiratory examination assessing for signs of both acute respiratory tract infection and chronic pulmonary disease. The use of makeshift pipes composed of glass, metal and plastic scraps to smoke crack cocaine means that the digits and oropharynx should be examined for infections and predisposing burns, cuts and irritation. Finally, while a patient is under the influence of cocaine, disinhibition, masking of symptoms and appetite suppression may result in injuries or poor selfcare. The examination should screen for injuries throughout the body and determine a baseline for weight and body habitus. ${ }^{1}$

What investigations should be arranged? A high-quality guideline from the Center for Substance Abuse Treatment, an agency of the US government, along with numerous highquality epidemiologic studies, informs key initial investigations for the patient. ${ }^{1}$ These investigations include, at a minimum, electrocardiography, complete blood count, liver function tests and liver enzyme tests. ${ }^{1}$ Screening for associated blood-borne and sexually transmitted diseases is equally important, particularly for $\mathrm{HIV},{ }^{3}$ hepatitis $\mathrm{C}^{4}$ and syphilis. ${ }^{5}$ Immunity testing for hepatitis $\mathrm{A}$ and $\mathrm{B}$, and a pregnancy test in women should also be considered. ${ }^{1}$ Finally, associations with TB should be investigated; this patient requires two-step Mantoux testing, given the noted exposure, and appropriate radiography if results are positive. ${ }^{6}$

\section{What interventions should be offered?}

Vaccination should be offered for hepatitis B (if the patient is not already immune), hepatitis $\mathrm{A}$,
Competing interests: None declared.

This article has been peer reviewed.

The clinical scenario is fictional.

Correspondence to: Lawrence Loh, lawrence. loh@utoronto.ca

CMAJ 2015. DOI:10.1503 /cmaj.150491 
influenza and pneumococcal disease, particularly if the patient is homeless or continuing with illicit drug use. ${ }^{7}$

Counselling should be provided about other potential risk behaviours and interventions, notably safe sex, medication compliance, and abstinence or harm reduction. Targeted referrals based on comorbidities, motivation and treatment preference may be made to psychiatry or counselling (e.g., for patients with comorbid mental illness), social work for marginalized patients (e.g., those who are homeless, unemployed or a new immigrant), addictions treatment (e.g., detoxification, if the patient is amenable to abstinence) and harm-reduction programs. ${ }^{1}$

\section{Is a referral to a harm-reduction program warranted?}

Various Canadian public health authorities have initiated programs for people who use crack cocaine. ${ }^{8}$ Among this population, using or sharing improper inhalation equipment (whether for financial, social or relational reasons) is a key modifiable behaviour associated with increased transmission of infectious diseases. ${ }^{9}$ Harm-reduction programs provide clean inhalation equipment (e.g., glass stems, mouthpieces, push sticks and brass screens) in an effort to reduce the harms associated with using ill-devised paraphernalia and sharing. ${ }^{8}$ Initial evaluations have shown associations between programs providing appropriately built crack pipes and reduced sharing, reduced crime and violence to obtain pipes, and reduced sourcing of pipes from the street, as well as transactional sex to obtain pipes..$^{10,11}$

The Working Group on Best Practices for Harm Reduction Programs in Canada has produced a two-part guideline on risky crack cocaine smoking and a more detailed overview of the evidence of effectiveness for various harm-reduction program models. ${ }^{12} \mathrm{~A}$ review of the guideline reveals that current evidence is lacking to compare harm reduction and abstinence approaches on the basis of improved health outcomes (rather than process and access outcomes); more robust data are needed for the working group to fully endorse the purported benefits of referral to programs for safer crack smoking. ${ }^{12}$

Further questioning is required to determine whether this patient would benefit from referral to a harm-reduction program.

\section{The case revisited}

The patient reports inhaling crack through purchased sterile glass pipes and denies using any makeshift pipes or sharing, but he was recently laid off and worries that he may have difficulty affording equipment in the future. He also wants assistance in decreasing his current usage.

A Mantoux two-step tuberculin skin test was negative. Additional blood tests for hepatitis B, hepatitis C, HIV and syphilis were negative, with other screening blood tests returning normal results. The blood tests also showed evidence of immunity to hepatitis B; the patient's immunizations were updated with vaccines for hepatitis A and pneumococcal disease, and he was educated about yearly influenza vaccines.

In view of the patient's concern and awareness of the risks of blood-borne pathogen transmission and willingness to seek care, he was provided with information on safer crack use. The physician consulted the local public health unit for information on local resources and subsequently referred the patient to a harm-reduction clinic for education and counselling, follow-up, and ongoing access to support services and the local safe inhalation kit distribution program.

\section{References}

1. Rawson RA, ed. Treatment for stimulant use disorders. Rockville (MD): Center for Substance Abuse Treatment; 1999.

2. Cacciola JS, Alterman A, Habing B, et al. Recent status scores for version 6 of the Addiction Severity Index (ASI-6). Addiction 2011;106:1588-602.

3. DeBeck K, Kerr T, Li K, et al. Smoking of crack cocaine as a risk factor for HIV infection among people who use injection drugs. CMAJ 2009;181:585-9.

4. Macías J, Palacios RB, Claro E, et al. High prevalence of hepatitis $\mathrm{C}$ virus infection among non-injection drug users: association with sharing the inhalation implements of crack. Liver Int 2008; 28:781-6.

5. Greenberg MS, Singh T, Htoo M, et al. The association between congenital syphilis and cocaine/crack use in New York City: a case-control study. Am J Public Health 1991;81:1316-8.

6. McElroy PD, Rothenburg RB, Varghese R, et al. A networkinformed approach to investigating a tuberculosis outbreak: implications for enhancing contact investigations. Int J Tuberc Lung Dis 2003;7:S486-S493.

7. Canadian immunization guide: Part 3. Ottawa: Public Health Agency of Canada; 2014.

8. Haydon E, Fischer B. Crack use as a public health problem in Canada: Call for an evaluation of 'safer crack use kits'. Can J Public Health 2005;96:185.

9. Fischer B, Prowis J, Firestone Cruz M, et al. Hepatitis C virus transmission among oral crack users: viral detection on crack paraphernalia. Eur J Gastroenterol Hepatol 2008;20:29-32.

10. Ivsins A, Roth E, Nakamura N, et al. Uptake, benefits of and barriers to safer crack use kit (SCUK) distribution programmes in Victoria, Canada: a qualitative exploration. Int J Drug Policy 2011;22:292-300.

11. Evaluation report: Vancouver. Vancouver Coastal Health Safer Smoking Pilot Project; 2013.

12. Strike C, Hopkins S, Watson TM, et al. Best practice recommendations for Canadian harm reduction programs that provide service to people who use drugs and are at risk for HIV, HCV, and other harms: Part 1. Toronto: Working Group on Best Practice for Harm Reduction Programs in Canada; 2013.

Affiliations: Department of Family Medicine (Sur), McMaster University, Hamilton, Ont.; Dalla Lana School of Public Health (Loh), University of Toronto, Toronto, Ont.

Contributors: Both authors contributed equally to the conception and design of the case study. Amy Sur drafted the article, which both authors revised. Both authors gave final approval of the version to be published and agreed to act as guarantors of the work. 